This item was submitted to Loughborough's Research Repository by the author.

Items in Figshare are protected by copyright, with all rights reserved, unless otherwise indicated.

\title{
Knowledge sharing: Insights from Campaign for Real Ale (CAMRA) Festival volunteers
}

PLEASE CITE THE PUBLISHED VERSION

https://doi.org/10.1108/IJEFM-11-2013-0028

PUBLISHER

(C) Emerald

VERSION

AM (Accepted Manuscript)

\section{PUBLISHER STATEMENT}

This work is made available according to the conditions of the Creative Commons Attribution-NonCommercialNoDerivatives 4.0 International (CC BY-NC-ND 4.0) licence. Full details of this licence are available at: https://creativecommons.org/licenses/by-nc-nd/4.0/

\section{LICENCE}

CC BY-NC-ND 4.0

\section{REPOSITORY RECORD}

Ragsdell, Gillian, and Allan Jepson. 2019. "Knowledge Sharing: Insights from Campaign for Real Ale (CAMRA) Festival Volunteers”. figshare. https://hdl.handle.net/2134/33375. 


\section{Introduction}

Managing knowledge is widely accepted as a way for organisations to improve their performance and gain competitive advantage (Oppong et al., 2005; Chang and Chuang, 2011; Holsapple and $\mathrm{Wu}, 2011)$. Although there was an initial emphasis on technology to drive knowledge management (KM) activities (Borghoff and Pareschi, 1997; Marwick, 2001; Bose and Sugumaran, 2003;), more recently a 'softer' (and perhaps more challenging) approach has been taken. Attention has, increasingly, been paid to cultural, social and human factors to support effective KM with, for example, Soliman and Spooner (2000) and Smith and McLaughlin (2004) suggesting a stronger focus on people-centric KM, and other researchers (e.g. Zheng et al., 2010) developing more holistic approaches.

In the same way that there has been an evolutionary movement in the dominant paradigm of $\mathrm{KM}$ practice, there has also been a change in focus with respect to the sectors in which KM practices and research have been undertaken. With the benefits of KM being most obviously applicable for increasing knowledge assets and adding to an organisation's intellectual capital, it is not surprising that the private sector was the first to capitalise on the implementation of KM strategies and was closely followed by the public sector (e.g. Bate and Robert, 2002; Cong and Pandya, 2003; Taylor and Wright, 2004). Compared to the prolific evidence of academic interest in $\mathrm{KM}$ in private and public sectors, evidence of academic interest in voluntary sector KM is scarce. Nonetheless, authors such as Lettieri et al (2004), Hurley and Green (2005), Hume and Hume (2008) and Ragsdell (2009) have contributed to this arena. Other, more specific, organisational contexts such as SMEs (DeSouza and Awazu, 2006; Wong and Aspinwall, 2005), projects and project organisations (Kasvi et al., 2003; Koskinen, 2004; Newell et al., 2006; Hanisch et al., 2008) have also provided insights into KM theory and practice.

Of particular interest to this paper is the synergy between $\mathrm{KM}$ and project management in the context of the voluntary sector. The recognition that benefits can accrue in an ever changing project environment where knowledge is managed both within and between projects is recognised as contributing to an organisation's success, in much the same way that it has helped in more permanently structured organisations (Love et al., 2005). Reich (2007, p8) gives a definition of $\mathrm{KM}$ within project management as:

Knowledge management in the context of a project is the application of principles and processes designed to make relevant knowledge available to the project team. Effective knowledge management facilitates the creation and integration of knowledge, minimises 
knowledge losses, and fills knowledge gaps through the duration of a project.

In the voluntary sector much work is carried out on a project basis - festivals are one example. Festivals and events are dynamic environments in which project management is practised; they offer fertile ground for investigation of KM yet, despite the significance of the relationship between volunteers and the sustainability of festivals in the public and voluntary sectors, are relatively unexplored in this respect. Neha et al (2008), Abfalter et al (2012), Stadler et al (2013) and Ragsdell et al (2013) are notable exceptions. In the case of the Campaign for Real Ale (CAMRA), festivals are important to the sustainability of the organisation. CAMRA organises around 200 festivals each year across the UK; these festivals provide opportunities to showcase real ale, increase membership and to generate surplus funds. So, festival management is a key activity for CAMRA volunteers.

Some CAMRA festivals have been running for nearly 40 years. Over the years, festival volunteers have gained extensive experience, know-how and expertise in organising successful festivals. However, the special characteristics of voluntary sector organisations can bring particular knowledge challenges in the management of festivals. If there is no formal KM strategy in place in a volunteer-led organisation, the discontinuous environment of the festival calendar and the transient nature of festival workers can mean that their knowledge is lost and festival skills have to be relearned by incoming volunteers. Explicitly managing knowledge can ensure its efficient creation, capture, storing, sharing and use - it can also reduce the need to regularly 'reinvent the wheel'.

An investigation into some of the KM processes in CAMRA festivals was the focus of a British Academy funded project and forms the basis of this paper. Knowledge sharing continues to be of interest to a range of researchers (e.g. Bock and Kim, 2002; Mei et al., 2004; Small and Sage, 2005; Cabrera and Cabrera, 2005; Riege, 2005; Cabrera et al., 2006; Sondergaard et al., 2007), and the focus on this process is retained in this paper - the distinctive factor is that the focus herein is on knowledge sharing in the voluntary sector. The literature on knowledge sharing in the voluntary sector is fairly limited in terms of the number of studies. However, what there is does offer a range of perspectives with Lettieri et al., (2004) reporting on research based in Italy, Gilmour \& Stancliffe (2004) giving views on the knowledge sharing on an international basis and with Ragsdell (2009) examining the local branch of a nationwide UK organisation whose core purpose is the dissemination of information to citizens. Findings and insights from these studies tend not to be limited by their particular cultures; rather results tend, on a European basis at least, to suggest similar issues. These studies suggest a bias towards informal methods for knowledge management with an emphasis on sharing tacit 
knowledge through low-tech and face to face interactions. There is also a suggestion that the maturity of the voluntary sector organisation influences its approach to managing knowledge and the level of formalisation and fragmentation that exists. These papers provided a backdrop for designing the CAMRA study.

\section{Research Design}

Identifying the barriers and enablers to sharing best practices in the voluntary sector is an important issue both to sustaining successful events and, in cases where event management is important to achieving their core objectives, to the future success of non-profit organisations. Hence, the project sought to identify what supports and what obstructs CAMRA festival volunteers in the sharing of their knowledge and expertise. The focus was on the knowledge associated with the processes of organising and managing festivals i.e. generally on the volunteers' tacit knowledge rather than on their explicit knowledge associated with, in the main, the products of the festivals. Three case study festivals were selected (based on factors such as longevity and size) and interviews and focus groups were employed therein to collect rich, qualitative data about knowledge sharing activities of festival committee members and festival workers. Other data collection methods such as surveys were considered but were not pursued on the basis that they were unlikely to support the interpretivist philosophy that a study on tacit knowledge aligns with. Analysis of the data provided a basis to improve understanding about managing festival knowledge.

Festival Selection Each festival was deemed to be 'successful' across a range of parameters including, but not exclusively, the generation of surplus funds and positive reviews of the event. They were also 'active' festivals in the sense that the festival had either recently taken place and the next one was already being planned, or that the festival was underway during the time of the pilot study, or that the festival was to take place in the near future. Of the three festivals, one was large and well established attracting many thousands of visitors (Festival A), the second was also well established but smaller in scale (Festival B) and the third (Festival C), was a small but recently re-established festival which had lapsed for a number of years. Table 1 summarises some details of the three different festivals and quantifies the spectrum from 'small' to 'large'.

\section{Table 1 Characteristics of Selected Festivals}

The different sizes, levels of maturity and site layouts of the three selected festivals encapsulated the range of CAMRA festivals and meant that the selection held the potential to illustrate different knowledge sharing practices and trigger a variety of insights about managing knowledge during event organisation in the voluntary sector. 
Semi-Structured Interviews Invitations to participate in interviews were sent to festival committee members whose roles would be representative of generic roles in other voluntary sector organisations involved in event management. This approach increased the possibility of transferability of any lessons learned from CAMRA to other volunteer-led organisations. So, where possible, those chosen for interview from each festival were the Festival Organiser, Treasurer, Health and Safety Officer, and Staffing Officer. Semi-structured interview schedules for the committee members were developed in part from themes identified from the literature, the aims and objectives of the work, and were focussed on the roles of individuals. Key areas explored were how festival personnel gained their knowledge and expertise, how they stored it, with whom and why they shared it, how it was shared and the barriers and enablers to so doing. The interviews were designed and undertaken in full acknowledgement of the reservations about, for example, internal and external validity, of researchers such as Diefenbach (2009) but were reassured by the experiences of researchers such as Carruthers (1990, p68) who overcame his reservations about the value of interviews once he recognised the "deeper understanding of the data" that he achieved by employing them.

Focus Groups In a similar vein, to guide the facilitation of focus groups, learning was taken from the experiences of Kitzinger (1994), Webb and Doman (2008) and Morgan (2010) who were all keen to stress the importance of the interaction between research participants which, in contrast to the interviewing process, brought new dynamics resulting in surfacing additional data. Unfortunately this was not a benefit realised from Festival C - since its volunteer base was comparatively small, there were insufficient volunteers to form a focus group. Thus, two focus groups were conducted each with five volunteers and with participants reflecting a wide range of differing responsibilities at their local festival. Focus group questions were developed in parallel with the interview schedules - the two sets of questions were very similar but worded and structured to accommodate interview participants as individuals or focus group members. With the benefit of hindsight, it was apparent that the facilitation of the focus groups was akin to the development of 'collective conversations' in keeping with the approach of Kamberelis and Dimitriadis (2013).

Data Presentation All interviewees and focus group participants had permitted the recording of their responses, enabling almost-verbatim transcripts to be made. Consideration was given to transcript analysis using proprietary software such as NVivo or ATLAS.ti, but it was decided to undertake analysis on a manual basis since there was some degree of consensus in the responses and the researchers' immersion in the data was seen as an advantage to this interpretivist approach. Transcripts were therefore presented using a cross tabular matrix (based on Cassell and Nadin, (2008)) where interview questions and responses by individuals 
and focus groups were summarised. An extract from one of the matrices of the results is shown in Table 2.

Table 2 Responses from Treasurers

\section{Data Analysis}

Once all the transcripts from each of the three festivals had been entered into the matrices, it was possible to highlight common themes related to the support and obstruction of knowledge sharing. This approach led to the identification of enablers and barriers to knowledge sharing within the festival context derived from an amalgamation of those evident in all of the three case study festivals. Common enablers and barriers to sharing knowledge were numerous and took various forms.

Authors such as Riege (2005), who identified at least three dozen barriers to knowledge sharing, have used various categories to distinguish between them. Riege's (2005) barriers were derived from a comprehensive literature review and were categorised as individual, organisational and technological barriers. This grounded and highly cited categorisation served as a useful way to structure both the composite list of enablers and of barriers identified in this study as shown in Tables 3 and 4 . Thus, this study went beyond simply categorising knowledge sharing barriers as Riege (2005) had done.

Table 3 Knowledge Sharing Enablers

Table 4 Knowledge Sharing Barriers

A cursory analysis of the two lists highlights a key difference and a key similarity. An obvious difference between the lists is the distinct emphasis on organisational enablers in Table 3 and the distinct emphasis on individual barriers in Table 4. This leads to an understanding that, while the (albeit temporary) organisational aspects of CAMRA festivals are noticeably supporting knowledge sharing, festival volunteers need further support (organisational and otherwise) in overcoming additional individual barriers. It was also interesting to note with respect to a key similarity, that both 'trust' and the 'use of email' appear in duplicate as enablers and barriers to knowledge sharing. These individual and technological concepts present a dichotomy for festival volunteers; there is a tension between their potential to contribute positively and negatively, which needs careful management.

The tension created by the duality of the concept of trust is quite complex and is discussed later with respect to individual barriers. The use of technology, particularly email, being recognised as both an enabler and a barrier is less complex. Its value as a communication method to share certain types of knowledge was appreciated but the volunteers were also 
aware of its limitations in codifying and, in turn, sharing tacit knowledge. Tacit knowledge includes the experiences of volunteers that have been internalised by each individual and which, often, are difficult to articulate. Thus tacit knowledge can be difficult to express in a form that makes it possible to pass on to other volunteers.

Deeper consideration of the lists of enablers and barriers triggered insights about effective knowledge sharing practices in the context of festivals. They are discussed in the next section.

\section{Insights into the Practices of Sharing Festival Knowledge}

The above section identified common enablers and barriers to knowledge sharing and organised them according to Riege (2005); i.e. whether they are associated with individuals, with the organisational context ie the festival, or with technology. It was clear that there was an abundance of organisational enablers and a plethora of individual barriers - this triggered an additional, and original, process of categorisation that would reduce emphasis on their generic nature and, in turn, highlight more distinctions. The resultant categories for the organisational enablers were labelled 'personalisation' and 'culture' and, the individual barriers were labelled 'accessibility issues', 'types of trust' and 'lack of succession planning'. They are shown in Tables 3 and 4 . While interconnections between categories cannot be ignored, the category labels are taken to form a coherent structure for the discussion herein.

\section{Organisational enabler 1 - personalisation}

Given that festival experience is more focused on 'know-how' rather than 'know-that', (ie tacit, rather than explicit, knowledge) it is not surprising that all three festivals tended to favour a personalisation strategy to the management of knowledge rather than a codification strategy (Hansen et al, 1999). The implementation of a personalisation strategy was explicitly undertaken by each festival using three distinct methods to share knowledge.

Method 1: Face to face post-festival reviews Although they were not valued to the same extent by each set of festival volunteers, all three festivals scheduled a post project review meeting (Von Zedtwitz, 2002; Schindler and Eppler, 2003) to offer a forum for the exchange of information and knowledge that would inform future festivals. This meeting, and subsequent planning ones, were seen as especially important by the smallest, newest festival as a prime opportunity to learn and a chance to circulate a report on its first festival. A Festival Officer reported "Certainly we will use the vast majority of stuff we had last year as a basis for this year. A lot of it has come out at meetings - obviously there are records there of what we discussed at the meetings where we talked about different things, different means of raising sponsorship, different means of obtaining equipment. We've moved along quite a long way." 
A reciprocal exchange of views and information with interested parties seemed to be the process whereby improvement cycles were instigated and recorded, and these would be used to prompt changes in the next and future festivals.

For the largest festival, post project review meetings seemed a less prominent occasion for the exchange of views and ideas with colleagues who were on the fringes of the festival organisation. This seemed, in particular, to be a reflection of its continuous operation and containment of a project mind-set. Festival Committee Members seemed to be engaged in a continuous review and improvement cycle that had its roots in a sub-committee structure; when faced with new problems these members seemed to innovate and improve their processes to match. These new processes then become the subject of discussion and lobbying by their sponsors and then are agreed, amended or rejected at steering group meetings. As one Festival Officer stated, "feedback from last year has already gone into this year." Thus knowledge sharing had become an intrinsic element of a continuous process of festival organisation rather than a standalone activity for review meetings.

Method 2: Job rotation When security measures allowed and there was a willingness to change roles, volunteers at all three festivals rotated jobs. As a means of increasing job satisfaction, job rotation has been a regular feature of human resource strategies (Earney and Martins, 2009) and the management of paid employees. However, with an emphasis on the 'cross functional interfaces' that Jansen et al, (2005) claim job rotation creates, it is a process that is being recognised as an important contributor to knowledge management strategies (Fong and Choi, 2009; Sun, 2010; Chong et al, 2011). In the case of the festivals, job rotation not only seemed to motivate some volunteers by offering variety in their responsibilities but it also proved to be an important vehicle for transferring and acquiring knowledge. In addition, it also helped in the building of social capital amongst volunteers and contributed to the development of a knowledge culture (the latter is discussed later).

Method 3: Master-apprentice model 'Learning by doing' approaches were often mentioned in the interviews as processes by which know-how was shared. Such approaches formed part of a strategy to embed knowledge and expertise within festival teams and, more broadly, in the organisation. The model most often used in this process was that of an master-apprentice style, where those who were new to the job worked with, shadowed or were mentored (Karkoulian et al., 2008; Hunt and Michael, 1983) by those that were experienced in the task, to varying levels depending on its complexity. A focus group participant from Festival B shared his experience of receiving knowledge from a 'master', "I've had instances where I need to know how to do something and I've gone up to certain people and said, 'right, I don't know 
how to do that; can you show me?'... They have said, 'Yeah, sure' and sorted it." For some participants, being recognised as a 'master' creates a sense of satisfaction - as another focus group member put it "I think with me, from explaining to other people what I do and show them how to do things, that gives me a good feeling inside," Once the newcomers (apprentices) become skilled, they are then left to do the work independently with the opportunity to seek more guidance from the 'master' as necessary. In time, the apprentices become the masters.

The strong commitment to this method of sharing knowledge led to insights about the layout of the festivals. When festivals were confined to a single building, this helped in the knowledge sharing process since those who are new to the work have a closer and more accessible route to expert knowledge. The additional benefit is that, even without the closeness that a single building brings, the apprentice-master model lends itself well to the building of a relationships based on trust.

\section{Organisational enabler 2 - culture}

In keeping with the increase in emphasis on the 'softer' issues of $\mathrm{KM}$, there has been a consistent flow of studies into cultural aspects of organisations and their ability to support the sharing of know-how (Sackmann, 1992; Banks, 1999; De Long and Fahey, 2000; Oliver and Kandadi, 2006). Although knowledge was not always shared (as discussed in the context of barriers to knowledge sharing in subsequent sections) the dominant culture of the three CAMRA festivals was one based on a strong motivation to share knowledge in order to 'do the job well'. Volunteers took great pride in undertaking their allocated responsibilities and working towards overall festival 'success'. Sometimes paid employment and a career structure can bring contractual arrangements, competition and pressure to meet individual targets; these factors are unlikely to support the high levels of trust exhibited in the festivals and the relaxed environment in which festival experience was shared. Thus, the voluntary context of the festivals contributed to the development of a knowledge culture (Oliver and Kandadi, 2006) and, in particular, that of an engaging environment (Nakano et al, 2013).

While all three festivals exhibited pride in a job well done, this was not expressed overtly, and seemed to be collectively understood rather than expressed in any open and congratulatory way. This aspect of the festival culture brought insights about rewards for knowledge sharing. There is debate regarding rewards for knowledge sharing in profit making organisations: questions arise as to the effectiveness of reward schemes for individuals and for groups and what form any rewards should take (Bock and Kim, 2002; Bartol and Srivastava, 2002). Questions as to whether paid employees should receive any reward for a process that is often perceived as integral to their role, create dilemmas for management. More complexity is 
generated in this respect from a volunteer perspective where the range of motivations for being involved in a festival is much more diverse (Clary et al., 1992).

Individual barrier 1 - accessibility

Festival volunteers suffered from the difficulties in meeting face to face and, as a consequence, their social interactions were limited outside of the time of the festival period. However, in addition to barriers to accessing each other, the volunteers endured challenges related to the accessibility of information that would support the sharing of knowledge.

Since some of the participants in this study were in employment, the time that they could give to volunteering was often restricted in terms of the amount and flexibility. Thus circumstances moved the volunteers away from a traditional team setting (Webster and Wong, 2008) and more towards that of a virtual team and the additional challenges they can bring. For example, regular attendance at planning meetings was not always possible and communications were sometimes difficult to synchronise thus increasing the challenges for the Festival Committees (Lee-Kelley, 2002). Coupled with a geographical separation and no permanent headquarter building to meet outside of the festival dates, it is surprising that the role of technology (Hayward, 2002) was not more prevalent. Despite the logistical struggles that they encountered, the volunteers preferred to proceed with face to face interactions as the primary vehicle for the sharing of festival knowledge.

Other insights from consideration of accessibility related to the ownership of knowledge and the uncertainty as to 'who knew what?' In a business organisation, this uncertainty might be overcome by a 'directory of expertise'. However, with the transient nature of a volunteer workforce and the lack of resources needed to develop such a database, such a solution is probably not realistic for managing festival knowledge. Whether the scenario of not declaring 'who knew what' was linked to some individuals devaluing their knowledge, is questionable. There were some volunteers did not seem to appreciate the value that their knowledge contributed to the festival and, on that basis, admitted that they had not appreciated the need to readily share it.

Another perspective on the notion of ownership of knowledge brought forth additional insights from this study. First, even when knowledge was codified, risks were being taken where individuals were the sole repositories of unshared knowledge which was critical to the success of the festival. This was apparent and acknowledged at, for example, the largest festival, where several individuals managed different festival processes almost exclusively themselves in complex spread sheets or database applications which, in their view, were difficult to share in any meaningful way. This situation, in turn, prompted questions about intellectual property 
rights. Securing intellectual property is a matter that is on most organisations' agendas and it was an organisational perspective that Grover and Davenport (2001) took in relation to knowledge management research. However, this study does not highlight organisational intellectual property but, instead, that of the individual - as a volunteer, it would be reasonable to assume that their codified knowledge belongs to them personally and that the festival has no legal rights to it.

\section{Individual barrier 2 - types of trust}

Various forms of trust came to light during this study - trust in the festival organisation process, trust in the quality of the knowledge being shared and trust in volunteers' abilities - which came together to support the trusting environment in which knowledge sharing is likely to thrive (Holste and Fields, 2010; Lilleoere and Hansen, 2011). However, in addition to the enabling qualities of the types of trust that were identified, the same types of trust were listed as barriers to knowledge sharing; this is a tension that was somewhat unexpected.

As the interview data was analysed more deeply, it was evident that it is the perceived level of trust that determines certain behaviours towards knowledge sharing. While trust is generally seen as an enabler of knowledge sharing, for some volunteers, 'too high a level of trust' was viewed as a barrier to effective knowledge sharing since complacency was seen to set in possibly supporting 'groupthink' (Janis, 1972, 1982) - and the need to create new knowledge was not recognised. Hence, sometimes know-how was not questioned and went uncontested; as a result, processes were left unchanged, were not improved, and the knowledge base did not develop. Similarly, a high level of trust in the organising process meant that some volunteers did not engage in sharing their knowledge. It was often only when there was little trust in the organising process that some volunteers would respond by perceiving a need to more readily share their experience. This was an insight that has not been emphasised in the literature but is something that stakeholders, particularly in the knowledge cultures that volunteer-led organisations can readily promote, need to be mindful of.

\section{Individual barrier 3 - restrictions on succession planning}

Within all the case study festivals, there was evidence of three individual barriers to knowledge sharing that, together, restrict each festival's ability to undertake succession planning. Thus, the culmination of individual barriers, in this case, created an organisational barrier to generating festival sustainability through knowledge sharing. The individual barriers were time, lack of appreciation of the value of knowledge and the ageing profile of volunteers. 
It is unsurprising that 'lack of time' is a regular reason for not sharing knowledge (Bartol and Srivastava, 2002; Riege, 2005; Cabrera et al, 2006). Particularly when 'time is of the essence' during festival set-up and take-down, legitimate criticisms can be levied at methods such as the master-apprentice model since the demonstration of a process can seem protracted. Often volunteers considered that it was 'quicker to do the job themselves than show someone else how to'. While this attitude produces the required outcomes in the short term, it is not an attitude that supports a long term vision of successful festival management. In addition to the problems that lack of time creates for festival volunteers and the sharing of their knowledge, in some cases volunteers did not appreciate the value of their knowledge. Thus, in ignorance of the advantages of sharing their knowledge, no efforts were made to do so, regardless of any time they might have available.

Overall, it was recognised that much festival knowledge is procedural and can be readily acquired with little instruction. At this level, a laissez faire approach to its codification and storage seemed appropriate given the depth and spread of expertise in CAMRA volunteers, and such knowledge could be safely left as local tacit knowledge in the heads of those who could readily share it. However, since some CAMRA festivals have been running for significant lengths of time, it is natural that some of the founding volunteers are reaching an age whereby they struggle to recall tacit knowledge and would prefer to work with explicit knowledge where possible. The movement from tacit knowledge to an explicit form requires its codification and, although there is appreciation of the value of doing this (Cowan and Foray, 1997; Sorensen and Lundh-Snis, 2001) there have been debates about the compromises that come from doing so (Hall, 2006).

Even though codification was mentioned by participants as a way of assisting in effective knowledge sharing by creating a record of the knowledge, it was not necessarily implied that sophisticated technological solutions would be found - after all, collections of photographs and images, hand written notes and informative posters were all mentioned as forms of codification. So, once again, computer technology was not at the forefront of volunteers' minds.; this, interestingly was not a reflection of the age group of the volunteers particularly but, nonetheless, could be a limiting factor in engaging in the codification process. It was interesting to note that when knowledge was proactively managed via codification, it tended to be in response to meet the needs of CAMRA for transparency. For example, it was codified for use in the development of budgets and to meet regulatory requirements in terms of health and safety and, in part, through post festival review meetings, to help festivals understand and improve their future performance.

\section{Lessons}


Neither the interpretivist position nor the case study approach used within this study allows for transferability of lessons and generalisation of results; the chosen philosophical stance and scope for the data collection call for some level of modesty in this respect. Notwithstanding that modesty, the fact that the focus was on the common enablers and barriers of three festivals undoubtedly increases the validity of the findings and their potential to inform other festivals' knowledge sharing activities. So, this final section summarises lessons for improving the sharing of festival knowledge based on the enhancement of the enablers and on the suppression or removal of barriers. The summary is underpinned by continued respect for the individuality of each festival and in acknowledgement that different insights might have been generated by another researcher; it also subscribes to the autonomy with which volunteer-led organisations operate and does not intend to be prescriptive.

Despite the dominance of individual barriers to knowledge sharing, most of the lessons call for organisational change and the responsibility for action would naturally fall into the remit of festival committee members. Firstly, the points relate to the further development of a personalisation strategy and a knowledge culture. Then they move into removing individual barriers by increasing accessibility, managing trust and encouraging individual contributions to succession planning.

From the findings of the study, the processes of sharing festival knowledge (especially tacit knowledge) and of developing a knowledge culture are clearly intertwined; one might say that they form a positive feedback loop. This means that, as more emphasis is placed on encouraging methods by which volunteers interact to share knowledge, the stronger the knowledge culture will become. Similarly, the greater emphasis there is on creating a knowledge culture, the more likely it is that volunteers will employ methods to share knowledge. There is no 'dis-connect' between the two processes in practice.

Some of the key insights emerged from discussion of personalisation of a knowledge management strategy and resultant lessons relate to enhancing this strategy via both the festival layout and the festival management process. Consideration of the festival layout from the volunteers' perspective can bring a range of positive effects. For example, a design that supports a social atmosphere and openness will promote more informal interactions and passing on of know-how. This might mean designing in local communal break out areas for volunteers whose responsibilities do not normally overlap, encouraging physical movement of volunteers through areas that they would normally be diverted from, and including a communal area where all volunteers must meet at some point (e.g. a central signing in area). In terms of festival organisation, the insights lead to the suggestion that planning meetings are scheduled at agreed times and locations with the realisation that this may mean being creative so as to 
accommodate outliers and shift workers. It also means encouraging and valuing contributions from all attendees.

Secondly, the study triggered insights about the individual barriers that, in turn, led to challenges for the organisation. These were in relation to factors such as accessibility of information and each other, the counter-intuitive responses to levels of trust and the inevitable ageing process of volunteers. A key example of a way that the festival organisation could overcome these individual barriers is by the introduction of a central store of information. $A$ central repository that captures procedural and domain knowledge could bring significant improvements. Such a system, whether technologically supported or not, would increase accessibility of knowledge for all volunteers and, with a wider spread of knowledge, would help to secure the sustainability of festivals. It would remove the risks that exclusivity of some knowledge was bringing. In addition, a central store would demonstrate an increase in transparency that would undoubtedly add to the openness of the prevailing culture. By offering volunteers the chance to access materials related to all aspects of a festival, they are more likely to have a realistic overview of the situation and to become more aware of the actual risks of a festival. In turn this new understanding might change (increase or decrease) their levels of trust and prompt more effective knowledge sharing. So, a technological change, such as this might be, holds the potential to incite individual, cultural and organisational changes too. Thus, the interconnectedness of the insights and lessons are reinforced further.

\section{Concluding Comments}

While this paper has focussed on the similarities between the festivals, it is true to say that differences were also identified and that the overarching study did not neglect them. A comparative analysis of the findings from the three festivals, discussed in Ragsdell et al (2013), showed that there were also differences in the way that they were organised and how volunteers acquired, shared and stored their know-how and expertise. The differences were partly reflected in the age and maturity of the festival, their size and, it is argued, the risks of success or failure associated with organising a particular festival. The differences do not detract from the contribution of this paper which has focussed on meeting one of the objectives of the study; hence, the emphasis herein has been on identifying common enablers and barriers to knowledge sharing. Their identification has led to particular insights and lessons which could prove useful in aiding festival organisers in their future management of knowledge and form a platform for further studies of knowledge practices in the voluntary sector.

\section{References}

Abfalter, D., Stadler, R. and Muller, J. (2012), "The organization of knowledge sharing at the Colorado Music Festival", International Journal of Arts Management, Vol. 14 No. 3, pp. 4-15. 
Banks, E. (1999) "Creating a knowledge culture”, Work Study, Vol. 48 No. 1, pp.18-20.

Bartol, K.M. and Srivastava, A. (2002), "Encouraging knowledge sharing: The role of organizational reward systems", Journal of Leadership and Organizational Studies, Vol. 9 No. 1, pp. 64-76.

Bate, S.P. and Robert, G. (2002), "Knowledge management and communities of practice in the private sector: lessons for modernizing the National Health Service in England and Wales", Public Administration, Vol. 80 No. 4, pp. 643-663.

Bock, G.W. and Kim, Y.G. (2002), "Breaking the myths of rewards: An exploratory study of attitudes of knowledge sharing", Information Resources Management Journal, Vol. 15 No.(2, pp. 14-21.

Borghoff, U.M. and Pareschi, R. (1997), "Information technology for knowledge management", Journal of Universal Computer Science, Vol. 3 No. 8, pp. 835-842.

Bose, R. and Sugumaran, V. (2003), "Application of knowledge management technology in customer relationship management", Knowledge and Process Management, Vol. 10 No.1, pp. 3-17.

Cabrera, E.F. and Cabrera, A. (2005), "Fostering knowledge sharing through people management practices", International Journal of Human Resources Management, Vol. 16, No. 5, pp. 720-735.

Cabrera, A., William, C.C. and Sagado, J.F. (2006), "Determinants of individual engagement in knowledge sharing", International Journal of Human Resource Management, Vol. 17 No. 2, pp. 245-264.

Carruthers, J. (1990), "A rationale for the use of semi-structured interviews", Journal of Educational Administration, Vol. 28 No.1, pp. 63-68.

Cassell, C. and Nadin, S. (2008), "Matrices analysis", in Thorpe, R. and Holt, R. (Eds.), The Sage Dictionary of Qualitative Research. Sage, London, pp.220-222.

Chang, T-C. and Chuang, S-H. (2011), "Performance implications for knowledge management processes: Examining the roles of infrastructure capability and business strategy", Expert Systems with Application, Vol. 38, pp. 6170-6178.

Chong, S.C., Salleh, K., Ahmad, S.N. and Sharifuddin, S-I.S.O. (2011), "KM implementation in a public sector accounting organization: an empirical investigation", Journal of Knowledge Management, Vol. 15 No. 3, pp. 497-512.

Clary, E. G., Snyder, M. and Ridge, R. (1992), "Volunteers' motivations: A functional strategy for the recruitment, placement, and retention of volunteers", Nonprofit Management and Leadership, Vol. 2, No. 4, pp. 333-350.

Cong, X. and Pandya, K.V. (2003), Issues of knowledge management in the public sector. Electronic Journal of Knowledge Management, Vol. 1 No. 2, pp. 25-33. 
Cowan, R. and Foray, D. (1997), "The Economics of codification and the diffusion of knowledge", Industrial and Corporate Change, Vol. 6 No. 3, pp. 595-622.

De Long, D.W. and Fahey, L. (2000), "Diagnosing cultural barriers to knowledge management", Academy of Management Executive, Vol. 14 No. 4, pp. 113-127.

Desouza, K.C. and Awazu, Y. (2006), "Knowledge management at SMEs: five peculiarities", Journal of Knowledge Management, Vol. 10 No. 1, pp. 32-43.

Diefenbach, T. (2009), "Are case studies more than sophisticated storytelling? Methodological problems of qualitative empirical research mainly based on semi-structured interviews", Quality and Quantity, Vol. 43, No. 6, pp. 875-894.

Earney, S. and Martins, A. (2009), "Job rotation at Cardiff University Library Service: a pilot study", Journal of Librarianship and Information Science, Vol. 41 No. 4, pp. 213-226.

Fong, P.S.W. and Choi, S.K.Y. (2009), "The processes of knowledge management in professional services firms in the construction industry: a critical assessment of both theory and practice", Journal of Knowledge Management, Vol. 13 No. 2, pp. 110-126.

Gilmour, J. and Stancliffe, M. (2004) Managing knowledge in an international organisation: the work of Voluntary Services Overseas (VSO). Records Management Journal, Vol. 14, No. 3, pp 124-128.

Grover, V. and Davenport, T.H. (2001), "General perspectives on knowledge management Fostering a research agenda", Journal of Management Information Systems, Vol. 18 No. 1, pp.5-21.

Hall, M. (2006), "Knowledge management and the limits of knowledge codification". Journal of Knowledge Management, Vol. 10 No. 3, pp.117-126.

Hanisch, B., Linder, F., Mueller, A. and Wald, A. (2008), "Knowledge management in project environments", Journal of Knowledge Management, Vol. 13 No. 4, pp. 148-160.

Hansen, M.T., Nohria, N. and Tierney, T. (1999), "What's your strategy for managing knowledge?" Harvard Business Review, Vol. 77, No. 2, , pp. 106-116.

Hayward, P.A. (2002), "A comparison of face-to-face and virtual software development teams", Team Performance Management, Vol. 8 No.1/2, pp. 39-48.

Holsapple, C.W. and Wu, J. (2011), "An elusive antecedent of superior firm performance: The knowledge management factor". Decision Support Systems, Vol. 52, No.1, pp. 271-283.

Holste, J.S. and Fields, D. (2010), "Trust and tacit knowledge sharing and use". Journal of Knowledge Management, Vol. 14 No. 1, pp. 128-140.

Hume, C. and Hume, M. (2008), "The strategic role of knowledge management in nonprofit organisations", International Journal of Nonprofit and Voluntary Sector Marketing. Vol. 13, No. 2, pp. 129-140.

Hunt, D.M. and Michael, C. (1983), "Mentorship: A career training and development tool". Academy of Management Review, Vol. 8 No. 3, pp. 475-485. 
Hurley, T.A. and Green, C.A. (2005), "Knowledge management and the nonprofit industry: a within and between approach". Journal of Knowledge Management Practice, Vol. 6, available at: http://www.tlainc.com/articl79.htm

Janis, I.L. (1972), Victims of groupthink: a psychological study of foreign-policy decisions and fiascoes, Houghton Mifflin, Boston.

Janis, I.L. (1982), Groupthink: psychological studies of policy decisions and fiascos, Houghton Mifflin, Boston

Jansen, J.J.P., Van den Bosch, F.A.J. and Volberda, H.W. (2005), "Managing potential and realized absorptive capacity: how do organizational antecedents matter?" Academy of Management Journal, Vol. 48 No.6, pp. 999-1015.

Kamberelis,, G. and Dimitriadis, G. (2013), Focus groups: from structured interviews to collective conversations, Routledge, Abingdon and New York.

Karkoulian, S., Halawi, L.A. and McCarthy ,R.V. (2008), "Knowledge management formal and informal mentoring: An empirical investigation in Lebanese banks", The Learning Organization, Vol. 15 No. 5, pp. 409-420.

Kasvi, J.J.J., Vartiainen, M. and Hailikari, M. (2003), "Managing knowledge and knowledge competences in projects and project organisations", International Journal of Project Management, Vol. 21, pp. 571-582.

Kitzinger, J. (1994), "The methodology of focus groups: the importance of interaction between research participants", Sociology of Health and IIIness, Vol. 16 No. 1, pp. 103-121.

Koskinen, K.U. (2004), "Knowledge management to improve project communication and implementation", Project Management Journal, Vol. 35 No. 1, pp. 13-19.

Lee-Kelley, L. (2002), "Situational leadership: Managing the virtual project team", Journal of Management Development, Vol. 21 No. 6, pp. 461-476.

Lettieri, E.M., Borga, F. and Savoldelli, A. (2004), "Knowledge management in non-profit organizations", Journal of Knowledge Management. Vol. 8 No. 6, pp. 16-30.

Lilleoere, A. and Hansen, E.H. (2011), "Knowledge-sharing enablers and barriers in pharmaceutical research and development", Journal of Knowledge Management, Vol. 15 No. 1, pp. 53-70.

Love, P.E.D., Fong, P.S.W. and Irani, Z. (Eds.), (2005), Management of knowledge in project environments, Elsevier, Oxford.

Marwick, A.D. (2001), "Knowledge management technology", IBM Systems Journal Vol. 40 No. 4, pp. 814-830.

Mei, Y.M., Lee, S.T. and Al-Hawamdeh, S. (2004), "Formulating a communication strategy for effective knowledge sharing", Journal of Information Science, Vol. 30 No. 1, pp. 12-22.

Morgan, D.L. (2010), "Reconsidering the role of interaction in analysing and reporting focus groups", Qualitative Health Research, Vol. 20 No. 5, pp. 718-722. 
Nakano, D., Muniz, J. and Batista, E.D. (2013), "Engaging environments: tacit knowledge sharing on the shop floor", Journal of Knowledge Management, Vol. 17 No. 2, pp. 290-306.

Neha, S., Pradeep, R. and Clark, H. (2008), "Knowledge mapping for safe festivals and events: An ontological approach", Event Management, Vol. 11 No.1/2, pp. 71-80.

Newell, S., Bresnen, M., Edelman, L., Scarbrough, H. and Swan, J. (2006), "Sharing knowledge across projects: Limits to ICT-led project review practices", Management Learning, Vol. 37 No. 2, pp. 167-185.

O'hEocha, C., Wang, X. and Conboy, K. (2012), "The use of focus groups in complex and pressurised IS studies and evaluation using Klein and Myers principles for interpretive research", Information Systems Journal, Vol. 22, No. 3, pp. 235-256.

Oliver, S. and Kandadi, K.R. (2006), "How to develop knowledge culture in organizations? A multiple case study of large distributed organizations", Journal of Knowledge Management, Vol. 10 No. 4, pp. 6-24.

Oppong, S.A., Yen, D.C. and Merhout, J.W. (2005), "A new strategy for harnessing knowledge management in e-commerce", Technology in Society, Vol. 27, No. 3, pp. 413-435.

Ragsdell, G. (2009), "Inhibitors and enhancers to knowledge sharing: lessons from the voluntary sector", Journal of Knowledge Management Practice, Vol. 10 No. 1, available at: http://www.tlainc.com/articl183.htm

Ragsdell, G., Ortoll-Espinet, E. and Norris, M. (2013), "Knowledge management in the voluntary sector: A focus on sharing project know-how and expertise", Knowledge Management Research and Practice, advance online publication 8 April 2013; doi: 10.1057/kmrp.2013.21.

Reich, B.H. (2007), "Managing knowledge and learning in IT projects: a conceptual framework and guidelines for practice", Project Management Journal, Vol. 38 No. 2, pp. 5-17.

Riege, A. (2005), "Three dozen knowledge sharing barriers managers must consider", Journal of Knowledge Management, Vol. 9 No. 3, pp. 18-35.

Sackmann, S.A. (1992), "Culture and subcultures: An analysis of organizational knowledge", Administrative Science Quarterly, Vol. 37 No. 1, pp.140-161.

Schindler, M. and Eppler, M.J. (2003), "Harvesting project knowledge: A review of project learning methods and success factors", International Journal of Project Management, Vol. 21 No. 3, pp. 219-228.

Small, C.T. and Sage, A.P. (2005), "Knowledge management and knowledge sharing: A review", Information and Knowledge Systems Management, Vol. 5, No. 3, pp.153-169.

Smith, P.A.C. and McLaughlin, M. (2004), "Knowledge management: People are important!" Journal of Knowledge Management Practice, Vol. 5, available at: http://www.tlainc.com/article160.htm 
Soliman, F. and Spooner, K. (2000), "Strategies for implementing knowledge management: The role of human resources", Journal of Knowledge Management, Vol. 4 No. 4, pp. 337-345. Sondergaard. S., Kerr, M. and Clegg, C. (2007), "Sharing knowledge: contextualizing sociotechnical thinking and practice", The Learning Organization, Vol. 14 No. 5, pp. 423-435.

Sorensen, C. and Lundh-Snis, U. (2001), "Innovation through knowledge codification", Journal of Information Technology, Vol. 16 No. 2, pp. 83-97.

Stadler, R., Reid, S, and Fullagar, S. (2013), "An ethnographic exploration of knowledge practices within the Queensland Music Festival", International Journal of Event and Festival Management, Vol. 4 No. 2, pp. 90-106.

Sun, P. (2010), "Five critical knowledge management organizational themes", Journal of Knowledge Management, Vol. 14 No. 4, pp. 507-523.

Taylor, W.A. and Wright, G.H. (2004), "Organizational readiness for successful knowledge sharing: Challenges for public sector management", Information Resources Management Journal, Vol. 17 No. 2, pp. 22-37.

Webb, C. and Doman, M. (2008), "Conducting focus groups: experiences from nursing research", Junctures, Vol. 10, pp. 51-60.

Webster, J. and Wong, W.K.P. (2008), "Comparing traditional and virtual group forms: identity, communication and trust in naturally occurring project teams", International Journal of Human Resource Management, Vol. 19 No. 1, pp. 41-62.

Wenger, E. (2000), "Communities of practice and social learning systems", Organization, Vol. 7 No. 2, pp. 225-246.

Wong, K.Y. and Aspinwall, E. (2005), "An empirical study of the important factors for knowledge-management adoption in the SME sector", Journal of Knowledge Management, Vol. 9 No. 3, pp. 64-82.

Von Zedtwitz, M. (2002), "Organizational learning through post-project reviews in R\&D", R\&D Management, Vol. 32 No. 3, pp. 255-268.

Zheng, W., Yang, B. and McLean, G.N. (2010), "Linking organizational culture, structure, strategy, and organizational effectiveness: Mediating role of knowledge management", Journal of Business Research, Vol. 63, pp. 763-771. 